\title{
Childhood Colorectal Carcinoma
}

National Cancer Institute

\section{Source}

National Cancer Institute. Childhood Colorectal Carcinoma. NCI Thesaurus. Code

C118808.

A rare colorectal carcinoma that occurs during childhood. 